\title{
Society for Pediatric Research 2012 Presidential Address: SPR strategic plan priorities 2012
}

\author{
Susan L. Furth ${ }^{1}$
}

On the Internet and in some circles, it has been predicted that December 2012 will herald some cataclysmic events, as this date has been rumored to be the end date of a 5,125-y-long cycle in the ancient Mayan calendar. Predictions of catastrophe abound, and a "2012" movie with blockbuster special effects depicting various natural disasters is due out at the end of the year.

A level of anxiety which sometimes flares into a sense of impending doom has also surfaced in the pediatric research community in 2012. During this calendar year, economic uncertainty, political standoffs, and threats of drastic budget cuts to programs supporting child health and pediatric research have made the future of pediatric research feel very uncertain. In this address, I will outline those threats but also highlight the strengths of the Society for Pediatric Research (SPR) organization, most visibly represented by (i) the focus of our strategic planning efforts, initiated over the last $2 \mathrm{y}$ and (ii) our outstanding membership, who demonstrate an unparalleled commitment to research promoting children's health. Focusing on our strategic priorities and leveraging the commitment of our members to promote research provides an opportunity for our community to overcome the threats to child health research on the immediate horizon.

The SPR was founded on the goal of fostering pediatric investigation and providing the opportunity for young scientists to present their work (1). From the origin of the society until today, SPR members have spent a substantial proportion of their time in research activities. As part of our recent strategic planning efforts, the SPR membership was surveyed to assess the proportion of time members devoted to different academic pediatric activities. Research efforts remain prominent throughout the careers of our members (Figure 1). When asked about what the key issues should be in the SPR's strategic plan, the membership responded that advocating for research and trying to keep young investigators in pediatrics and in pediatric research were the main goals. Furthermore, the members expressed an eagerness to be more involved with the activities of the society if given the opportunity (Figure 2).

As research is such a prominent part of our society's efforts, the activities of the US members of our society are tightly linked with funding from the National Institutes of Health (NIH). Threats to NIH funding, particularly funding of awards for new investigators, are of substantial concern to our membership. Although the NIH currently invests $\$ 30.6$ billion in medical research (2), after adjustment for inflation, the fiscal year (FY) 2012 NIH budget and the president's proposal for the NIH for FY 2013 were the lowest since FY 2001 (Figure 3) (3). The number of research project grants funded by the NIH has declined since 2004 (Figure 4) (3). Over the last decade, success rates for grant applications have fallen dramatically and there is no reason to expect improvement in FY2012-2013 (Figure 5) (3). The failure of the "super committee" to achieve a budget deal this past summer has left the looming threat of across-the-board budget cuts known as "sequestration," which, in the absence of congressional action, may result in an additional $11.1 \%$ ( $\$ 2.8$ billion) reduction in the NIH extramural budget according to a recent report from the Federation of American Societies for Experimental Biology (FASEB) (4). These cuts will have substantial impact on the quality and quantity of pediatric research.

An additional focus of the SPR since its inception has been the focus on the young investigator. At its outset, the society included in its membership requirements an age limit of $<45 \mathrm{y}$ to become an active member (1). Therefore, an additional threat to the main principles of our society is the recent diminished support of programs that contribute to the career development of future child health researchers. In the current budget climate, Children's Hospitals Graduate Medical Education (CHGME), the Title VII health professions programs, and the support of other training, including graduate medical education (GME) and the Health Careers Opportunity Program (HCOP), are under threat. Funding for CHGME was initially left out of the president's FY12 budget and then restored but with a $15 \%$ reduction (from $\$ 317.5$ million to $\$ 267.0$ million). The FY13 budget has a further 67\% reduction in CHGME funding (from $\$ 267$ million to $\$ 88$ million). Medicare-based GME is similarly threatened (5). In 2011, the Bowles-Simpson Commission recommended reducing direct and indirect payments for Medicare GME by $\$ 6.0$ billion (6). Fortunately, the Affordable Care Act strengthens support for pediatric primary care, subspecialty, and surgical specialty workforce through Title VII programs, and a number of organizations continue to lobby Congress to raise awareness of the importance of ongoing support for GME, children's hospital GME, and training support. 


\section{SpecialArticle | Furth}

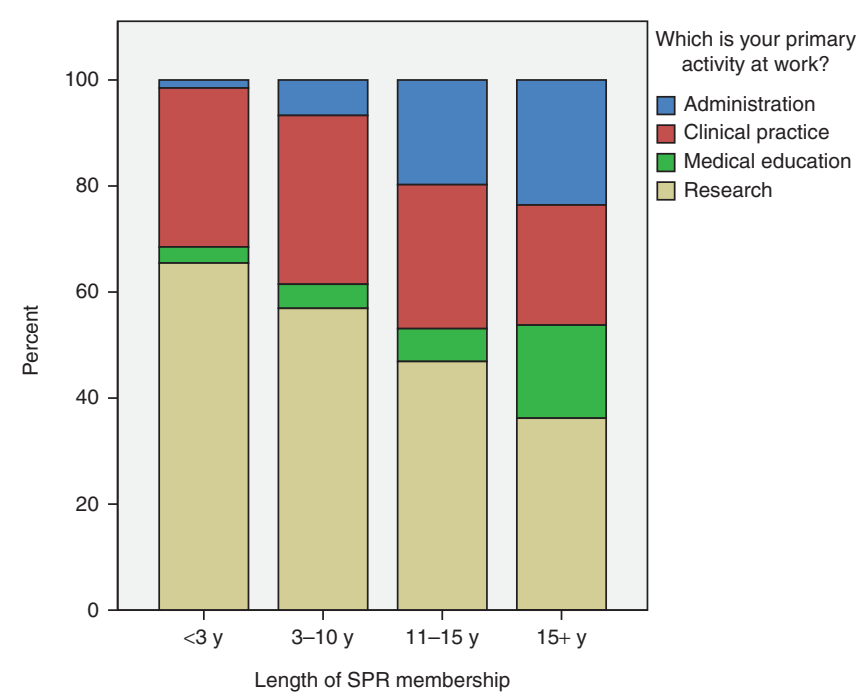

Figure 1. Primary activities of Society for Pediatric Research (SPR) members by length of SPR membership.

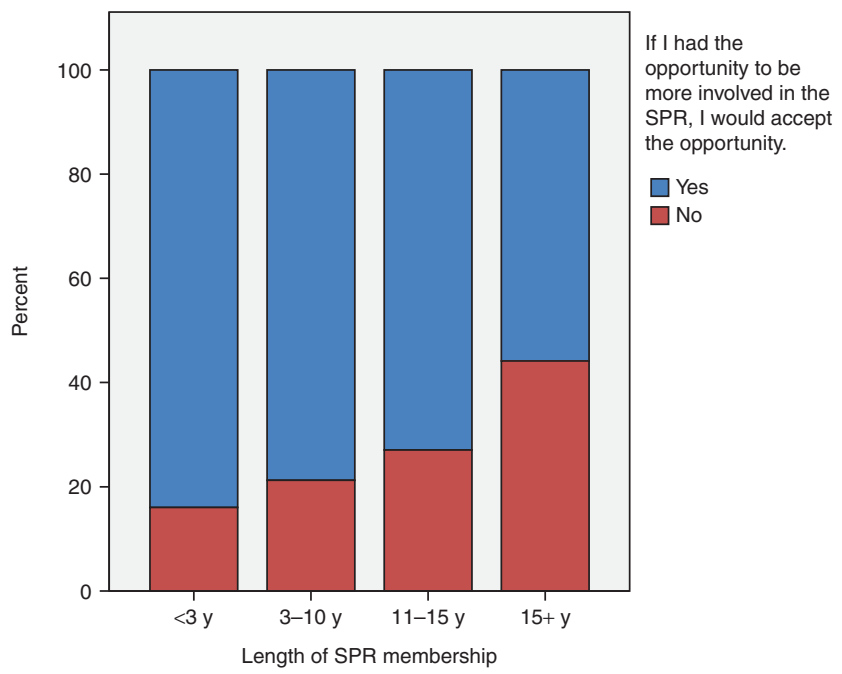

Figure 2. Willingness of Society for Pediatric Research (SPR) members to become more involved in SPR activities by length of SPR membership.

What can an organization such as the SPR do to counter some of these threats to the core values of our membership? What are the strengths that we can leverage? As of April 2012, the Society had 3,245 total members. In 2010, we embarked on a strategic planning process to focus the goals for our society and tailor these to the priorities of our membership. The full content of the strategic plan can be viewed at http://www.aps-sprorg. As part of the strategic planning process, the SPR membership was surveyed to identify our core priorities. We refocused our mission statement: "The Society for Pediatric Research exists to foster the research and career development of investigators engaged in creating new knowledge that advances the health and well-being of children and youth." We identified three strategic objectives: (i) to increase the value of the SPR to its members; (ii) to increase impact of pediatric research by increasing the quantity, quality, and dissemination of pediatric research, and (iii) to increase the financial stability of the organization.

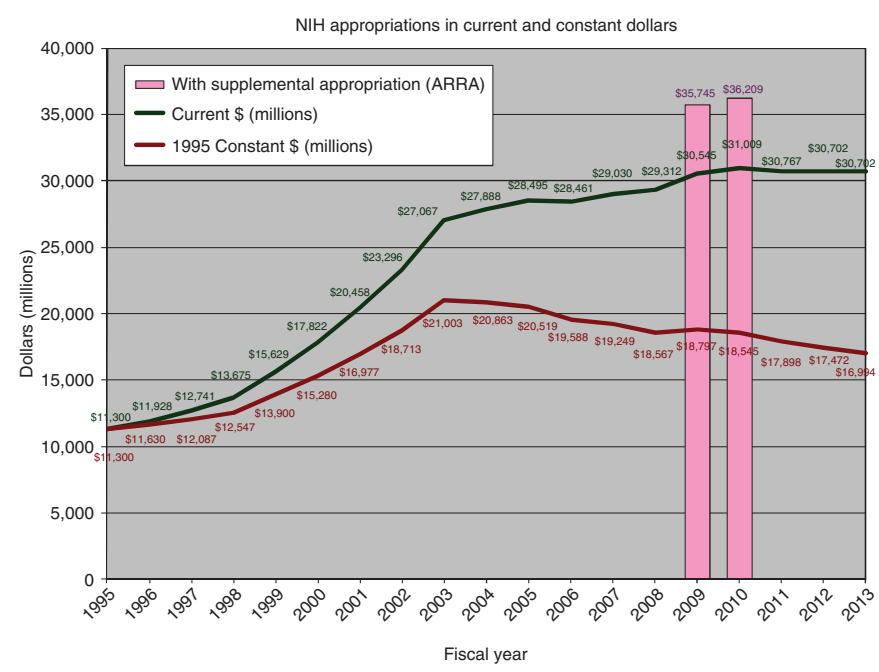

Figure 3. National Institutes of Health $(\mathrm{NIH})$ appropriations in current and constant dollars 1995-2013. From "NIH Research Funding Trends FY1995-2012," by Kim Ngo and Howard Garrison. Reprinted with permission from the Federation of American Societies for Experimental Biology, 2012 (http://www.faseb.org).

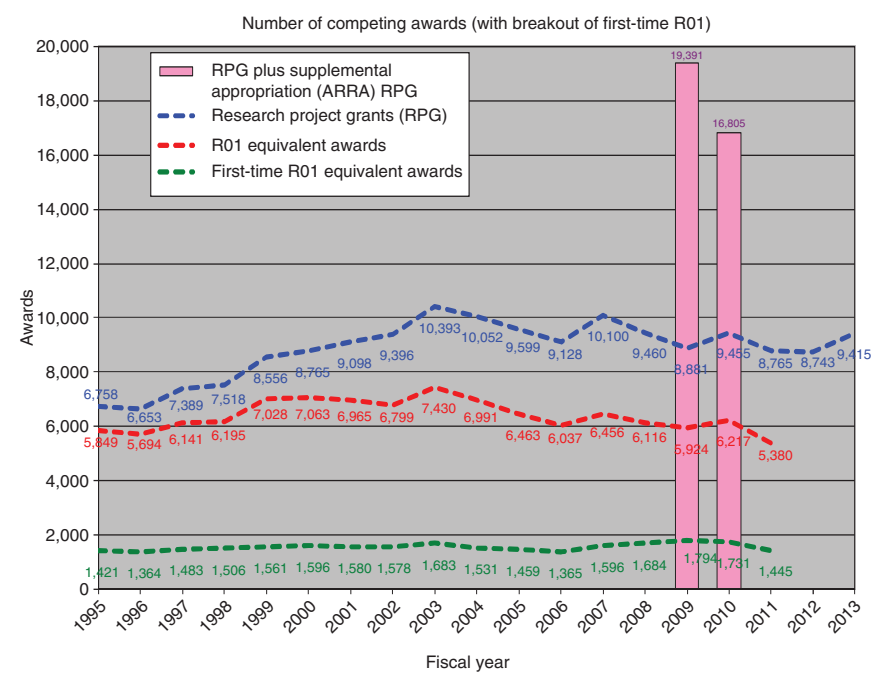

Figure 4. Number of National Institutes of Health $(\mathrm{NIH})$ competing research project grant awards 1995-2013. From “NIH Research Funding Trends FY1995-2012," by Kim Ngo and Howard Garrison. Reprinted with permission from the Federation of American Societies for Experimental Biology, 2012 (http://www.faseb.org).

In order to increase the value of SPR to its membership, we have embarked on efforts to improve communication to our members, through the development of a communications committee, a revamping of our website at http://www.aps-spr. org, and a quarterly newsletter, including updates on advocacy and policy to activate our members to work to support funding for research and training of future child health researchers. We have developed a new fellows section for membership, where fellows can join free of charge and learn more about the workings of the SPR. The fellows section will provide fellows with a variety of resources and educational offerings to facilitate transition from fellowship to junior faculty and the initiation 


\section{SPR 2012 Presidential Address $\quad$ Special Article}

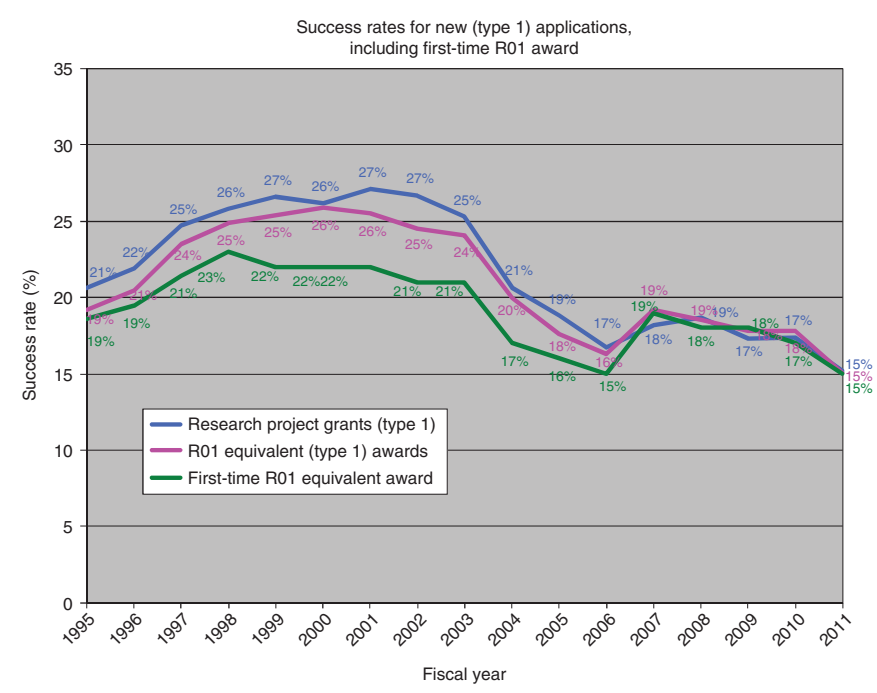

Figure 5. Success rates for new National Institutes of Health $(\mathrm{NIH})$ applications 1995-2011. From "NIH Research Funding Trends FY19952012," by Kim Ngo and Howard Garrison. Reprinted with permission from the Federation of American Societies for Experimental Biology, 2012 (http://www.faseb.org).

of a successful research career. Through a Young Investigator Coaching Program, we hope to link more senior, successful investigators with junior members to provide guidance in navigating career growth in the academic pediatric research setting. This is a new program, and it will complement the efforts of the long-running, successful student research program that funds over 45 students in an 8-10 wk pediatric laboratory experience each summer in an effort to strengthen the pipeline of pediatric researchers.

To counter the threats to research funding and training outlined above, an advocacy committee was also developed in the context of the strategic plan. Members of the SPR advocacy committee are integrated into the Public Policy Council (PPC), which combines the legislative advocacy efforts of the American Pediatric Society, the SPR, the Association of Medical School Pediatric Department Chairs, and the Academic Pediatric Association. The PPC works closely with the Department of Federal Affairs for the American Academy of Pediatrics. In addition to its work with the PPC, the SPR has joined FASEB. As the first pediatric research society to join this organization, we hope to broaden its long track record in effectively supporting research funding with further support for child health research. Through our collaboration with these organizations, we encourage our SPR members and our fellow pediatricians to communicate with their representatives at the state and federal level that support for child health training and research programs improves child health, and accelerates the search for cures for diseases that affect the youngest and most vulnerable among us.

Finally, as part of the SPR's strategic plan, we hope to increase awareness about and support for pediatric research with an annual "Run for Pediatric Research." The first fun-run was held at the 2012 Pediatric Academic Society Meeting in Boston, and will become an annual event to raise money and visibility for the important work of our society.

The membership of the SPR has changed dramatically since its first meeting in Boston on 29 March 1929 with 25 men in attendance. Annual dues were $\$ 2.00$ at that time. The first women were admitted to the Society in 1934, and in 1952, almost 20 years after that, the first African-American was elected to become a member. In the 83 years of its existence, the SPR has changed, growing from 25 to more than 3,200 members, yet its goals are remarkably similar to the originally stated purpose; to foster pediatric investigation and to provide opportunity for younger scientists to present their work. Despite the threats to these goals that exist in today's economic climate, the priorities of our membership in supporting research and training persist. Our strategic plan will facilitate our membership's ability to actively participate in championing the goals of the SPR and promote action to support research funding and training for the future research leaders in pediatrics for the 21 st century.

\section{REFERENCES}

1. Weil WB Jr. The Society for Pediatric Research: from infancy to adulthood in sixty-five years. Pediatrics 1996;97:129-36.

2. NIH-Related Provisions in the Conference Agreement on the Consolidated Appropriations Act, 2012 [H.R. 2055; House Report 112-331].

3. Ngo K, Garrison H; Federation of American Societies for Experimental Biology, Policy and Government Affairs. "NIH Research Funding Trends FY 1995-2012." (http://www.faseb.org/Policy-and-Government-Affairs/ Data-Compilations/NIH-Research-Funding-Trends.aspx.)

4. Federation of American Societies for Experimental Biology. Sequestration Would Deal A Devastating Blow to Medical Research. (http://www.faseb. org/Portals/0/PDFs/opa/4.16.12\%20Sequestration\%20and\%20the $\% 20$ NIH\%20pdf.pdf.)

5. Iglehart JK. The uncertain future of Medicare and graduate medical education. N Engl J Med 2011;365:1340-5.

6. Iglehart JK. Financing graduate medical education-mounting pressure for reform. N Engl J Med 2012;366:1562-3. 